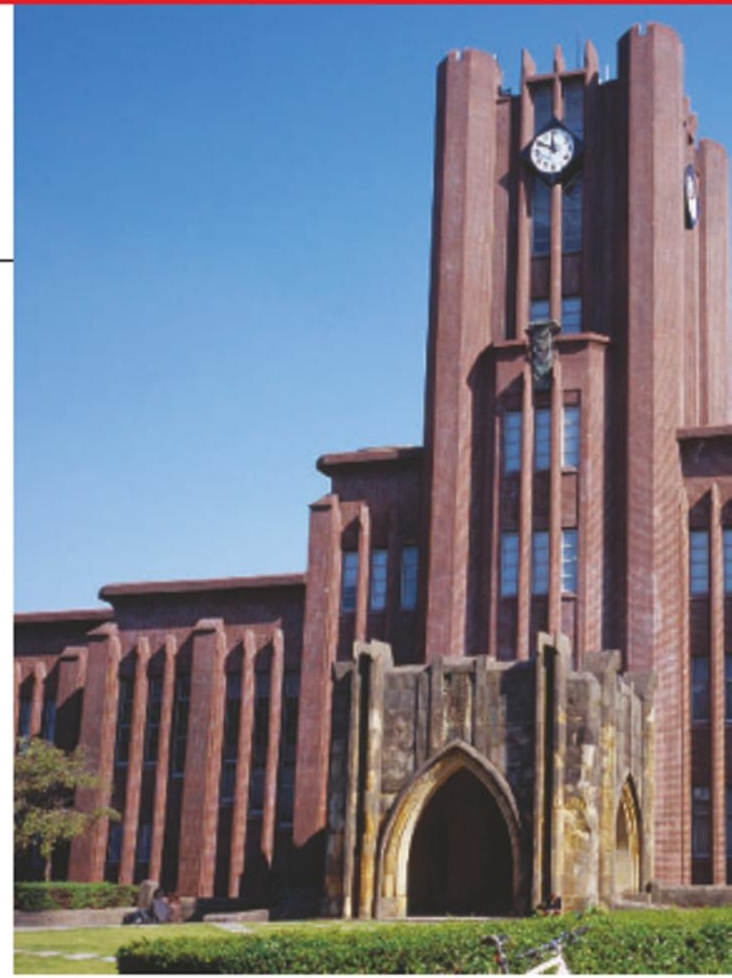

A University of Tokyo investigation has found the possibility of wrongdoing bysome of its researchers.

The university selected a few of the papers and asked Taira to submit raw data by September. He failed to do so, blaming Kawasaki for allegedly not keeping good notebooks and storing back-up data on a computer that broke. The committee extended the deadline to the end of March, but again no evidence of reproducibility emerged.

A separate investigation was undertaken by the National Institute of Advanced Industrial Science and Technology (AIST), where Taira had headed a gene-discovery centre. Misconduct in nine of the twelve papers, it reported on 3 March, "could not be ruled out". One other paper was in the clear, and two were not scrutinized as they did not involve AIST research. Last week, the institute announced that it

\title{
Doubts over evolution block funding by Canadian agency
}

\begin{abstract}
A Canadian federal agency has denied funding to a scienceeducation researcher partly because of its doubts about the theory of evolution.

Brian Alters, director of the Evolution Education Research Centre at MoGill University in Montreal, had proposed a study of the effects of the popularization of intelligent design - the idea that an intelligent creator shaped life - on Canadian students, teachers, parents, administrators and policy-makers.
\end{abstract}

At a publiclecture on $29 \mathrm{March}$,

\author{
Alters revealed excerpts from \\ the rejection letter he received \\ from the Social Sciences and \\ Humanities Research Council \\ (SSHRC). The letter stated that, \\ among its reasons for rejection, \\ the committee felt there was \\ inadequate "justification for \\ the assumption in the proposal \\ that the theory of evolution, and \\ not intelligent-design theory, \\ was correct." \\ "It illustrates how the \\ misunderstanding of evolution \\ and intelligent design can go to \\ all levels of Canadian society,"
}

says Alters. David Green, director of MoGill University's Redpath natural-history museum, adds: "I was quite surprised that such an opinion could be tendered by a highpowered granting agency."

The SSHRC is the top socialsciences funding agency in Canada. Spokeswoman Eva Schacherl says its funding decisions are based on the comments submitted by a committee of peer reviewers, and that the council cannot comment on the sentence in question.
"We rely on the expertise of our committees to make recommendations," she says. Susan Bennett, an English professor at the University of Calgary in Alberta and chair of the SSHRC committee, could not be reached for comment by the time Nature went to press.

The maximum value of Alters's requested grant was Can $\$ 40,000$ (US\$34,000). He has received funding from the SSHRC before; for instance, his centre was awarded a Can $\$ 175,000$-grant to study the understanding of 


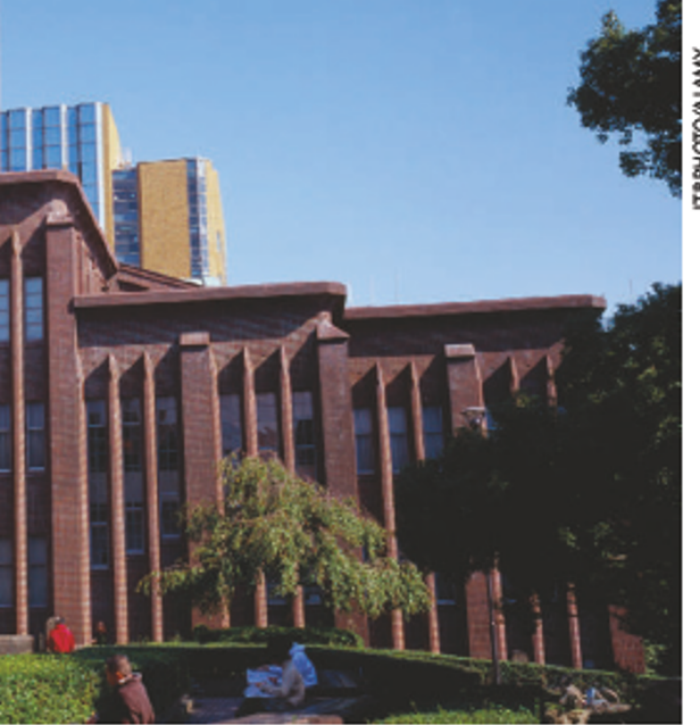

would not renew Taira's contract, which ended on 31 March.

A separate committee, set up earlier this year at the University of Tokyo, interviewed Taira, Kawasaki and other lab members about the lab's management and the possibility of misconduct. It plans to report to the university's president by 10 April, and to pass the issue to the university's disciplinary panel, which will decide possible penalties in the next few months.

Ichiko Fuyuno

Additional reporting by David Cyranoski

1. Kawasaki, H\& Taira, K Nature 423, 838-842(2003).

2 Kawasaki, H, Suyama, E, lyo, M. \& Taie, K. Nucleic Acids Res. 31, 981-987 (2003).

3 Kawasaki, H. Taira, K Nature 431, 211-217(2004)

4. Kawasaki, Hetal. Nature Biotechnol.20,376-380 (2002).

5. Kawasaki, H.\& Taira, K.EMBORep 3,443-450 (2002).

biological evolution in Islamic societies. Jennifer Robinson, associate viceprincipal for communications at McGill, says the university will ask the council to review its decision. "In ourview it is a factual error," she says. "The theory of evolution is a well-established science, and intelligent design is a religious belief.

Philip Sadler, a board member of the centre and director of science education at the Harvard-Smithsonian Center for Astrophysics in Cambridge, Massachusetts, is more philosophical. "If he was trying to answer the question as to whether all this popularization had had an impact, he just saved the government $\$ 40,000$," says Sadler. "He found the evidence without doing the study." Hannah Hoag

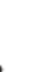

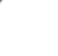

\section{Korean science powerhouse sends Nobel laureate packing}

Perhaps the relationship never had a chance. Robert Laughlin, who shared the 1998 Nobel Prize in Physics for his work on quantum fluids, was hired in July 2004 toreform the Korea Advanced Institute of Science and Technology (KAIST) in Daejeon. Last week, the institute's board of trustees decided not to renew his two-year contract.

Laughlin, formerly of Stanford University in California, was recruited by the office of South Korea's president, Moo Hyun Roh, to help shake up the country's university system. The reforms he proposed were fairly standard from a US perspective: he advocated competitive hiring of faculty at market rates; expanding the undergraduate student body; and running preparatory undergraduate degrees in medicine, law and business.

Many of KAIST's 400 or so

professors did not agree with Laughlin's approach. Of 278 that took part in a vote, $89 \%$ said they did not want him to continue. Choon Sup Yoon, a condensed-matter physicist who heads the faculty association, says that Laughlin's plans to expand the university's professional schools and humanities departments would have underminedKAIST's traditional status as a science and technology powerhouse. "His philosophy is totally different from what KAIST is about," says Yoon.

Another KAIST researcher, who did not want to be named, says the problem was more to do with Laughlin's attitude.

"The content was not that bad. Buthe made enemies, probably because of a lack of experience in running an organization," he says.

Laughlin admits thathe

lacked experience, but says that was not the real problem. The point of his dismissal, he says, "was to discredit the policy of hiring outsiders".

It was a stormy end to a bitter affair in which Laughlin was even at times accused of abusing his vacation privileges. Some say it wasinevitable. Chan-Mo Park, head of Pohang University of Science and Technology where Laughlin still holdsa post as distinguished professor, says that philosophies simply clashed. "Everything resulted from a cultural difference between the two countries," says Park. "It's a very sad story."

Laughlin finishes at KAIST inmid-July and will return to Stanford to resume teaching in the autumn.

David Cyranoski

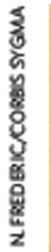

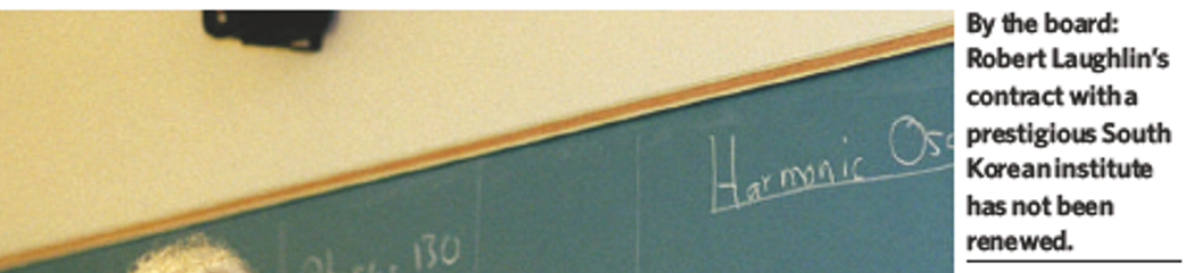

